101 PROGRAMMED INTERMITTENT EPIDURAL BOLUSES (PIEB) FOR LABOR ANALGESIA: THE EFFECTS ON MATERNAL MOTOR FUNCTION

${ }^{1}$ E Upryamova*, ${ }^{2} E$ Shifman, ${ }^{2}$ A Ovezov. ${ }^{1}$ Moscow Regional Scientific Research Institute of Obstetrics and Gynecology, Moscow, Russian Federation; ${ }^{2}$ Moscow Regional Research and Clinical Institute (MONIKI), Moscow, Russian Federation

\subsection{6/rapm-2021-ESRA.101}

Background and Aims The PIEB technique is a promising approach that demonstrates certain advantages over traditional techniques epidural analgesia. We compared the incidence of motor block $(\mathrm{MB})$ in women who received PIEB or traditional techniques for maintenance of labor analgesia.

Methods We studied 145 subjects. Term women with spontaneous labor and cervical dilation $>1-2 \mathrm{~cm}$ were eligible to participate in the study. All parturients divided into 5 groups:

1. manual boluses (levobupivacaine $0.25 \%-10.0 \mathrm{ml}$ );

2. PCEA (levobupivacaine $0.125 \%-10.0 \mathrm{ml}$ every 30 ');

3. CEI $(0.125 \%-10.0 \mathrm{ml} /$ hour $)+$ PCEA (levobupivacaine $0.125 \%-10.0 \mathrm{ml}$ every $\left.30^{\prime}\right)$;

4. CEI $(0.0625 \%-15 \mathrm{ml} /$ hour $)+$ PCEA $(0.0625 \%-10.0 \mathrm{ml}$ every $\left.20^{\prime}\right)$;

5. PIEB $\left(0.0625 \%-9.0 \mathrm{ml}\right.$ every $\left.45{ }^{\prime}\right)+$ PCEA $(0.0625 \%-$ $10.0 \mathrm{ml}$ every $\left.10^{\prime}\right)$.

The level of the motor block evaluated by the classic Bromage scale (0-1-2-3).

Results $\mathrm{MB}$ was reported in $80 \%$ in the 1 group by the 120th minute after analgesia, $78 \%$ and $52 \%$ in the 2 and 3 groups by the by 150 ' $(\mathrm{p}<0.001)$; In group 4 , the MB frequency is $6 \%$ after 15 ' the start and was increasing to $40 \%$ at full cervical dilation $(\mathrm{p}<0.001)$. In group 5 , the relative MB frequency did not exceed $10 \%$ by $120^{\prime}$ and was $0 \%$ at full cervical dilation $(\mathrm{p}<0.00001)$.

Conclusions The PIEB technique showed the greatest effectiveness for labor pain relief with a minimum frequency of $\mathrm{MB}$ development.

\section{OBSTETRIC HIGH BMI NEURAXIAL SURVEY}

Y Mustafa*, E Hindle. Birmingham Women's Hospital, Birmingham, UK

10.1136/rapm-2021-ESRA.102

Background and Aims Ultrasound-guided central neuraxial blockade (CNB) has been shown to reduce the number of insertion attempts in high BMI parturients.[1] The objective of this project was to gather data on our $\mathrm{CNB}$ practice for $\mathrm{BMI}$ $>40$ parturients at a busy UK obstetric unit.

Methods An online data collection form was used to identify the type of $\mathrm{CNB}$ undertaken, BMI, use of pre-procedural ultrasound, number of intervertebral spaces used, number of skin punctures made, number of re-angulations, use of a second operator, success rate and time taken for spinals.

Results Over a period of 7 weeks, $31 \mathrm{CNBs}$ were performed in parturients with $\mathrm{BMI}>40$. $23 \mathrm{CNBs}$ were undertaken without the use of pre-procedural ultrasound, whereas 8 used ultrasound beforehand. In the ultrasound group, a median of 1 intervertebral space was used, 1 skin puncture was made, 1 re-angulation occurred, a second operator was never needed, all CNBs were ultimately successful and the mean time for spinals was 2.13 minutes. This compares to the non-ultrasound group, where a median of 1 intervertebral space was used, 2 skin punctures were made, 3 re-angulations occurred, a second operator was used twice, two CNBs (both epidurals) were ultimately unsuccessful and the mean time for spinals was 5.67 minutes.

Conclusions The use of pre-procedural ultrasound in BMI $>40$ parturients results in quantitatively more successful CNBs. The time taken for spinals, in particular, reduced by more than half (with a mean time-saving of over 2.5 minutes per spinal) which could make a significant difference to clinical outcome in emergency caesarean sections.

\section{ANALGESIC EFFECT OF ERECTOR SPINAE PLANE BLOCK AFTER CAESAREAN SECTION: A RANDOMIZED CONTROLLED TRIAL}

${ }^{1}$ A Dostbil ${ }^{*},{ }^{1}$ I Ince, ${ }^{2} \mathrm{E}$ Yamak Altınpulluk, ${ }^{3} \mathrm{MF}$ Perez, ${ }^{1} \mathrm{U}$ Peksoz, ${ }^{4} \mathrm{G}$ Cimilli, ${ }^{5} \mathrm{~K}$ Kasali, ${ }^{1} \mathrm{C}$ Atalay, ${ }^{1} \mathrm{O}$ Ozmen, ${ }^{4} \mathrm{~T}$ Sahin, ${ }^{4} \mathrm{EP}$ Yılmaz. ${ }^{1}$ Ataturk University School of Medicine, Department of Anesthesiology and Reanimation, Erzurum, Turkey; ${ }^{2}$ Istanbul UniversityCerrahpasa, Cerrahpasa Medical Faculty, Department of Anaesthesiology and Reanimation, Istanbul, Turkey; ${ }^{3}$ Hospital Universitario de Móstoles,Department of Anesthesia, Madrid, Spain; ${ }^{4}$ Ataturk University School of Medicine, Department of Obstetrics and Gynecology, Erzurum, Turkey; ${ }^{5}$ Ataturk University School of Medicine, Department of Biostatistics, Erzurum, Turkey

\subsection{6/rapm-2021-ESRA. 103}

Background and Aims We hypothesized that bilateral erector spinae plane block applied from the transverse process of T9 who underwent elective cesarean section could provide effective postoperative analgesia.

Methods Fifty parturients who were in 38-42 gestational weeks who were scheduled to undergo elective cesarean section under spinal anesthesia were included in the study. Group I $(n=25)$ was categorized as the group in which spinal anesthesia alone (SA) was performed,Group II $(n=25)$ was categorized as the group in which SA+ESP block was performed.All patients were given a solution containing $7 \mathrm{mg}$ isobaric bupivacaine $+15 \mu \mathrm{g}$ fentanyl intrathecally through spinal anesthesia.The SA+ESP group,the bilateral ESPB was performed at the level T9 with $20 \mathrm{ml} 0.25 \%$ bupivacaine $+2 \mathrm{mg}$ dexamethasone immediately after the operation.Total fentanyl consumption in $24 \mathrm{hrs}$, visual analogue scale (VAS)score for pain,time to the first analgesic request were evaluated postoperatively.

Results The total fentanyl consumption in 24 hours was statistically significantly lower in the SA+ESP group than the SA group $(279 \pm 242.99 \mu \mathrm{g}$ vs. $423.08 \pm 212.55 \mu \mathrm{g}$, respectively, $\mathrm{p}=0.003)$. The first analgesic requirement time was statistically significantly shorter in the SA group than the $\mathrm{SA}+\mathrm{ESP}$ group $(150.20 \pm 51.83 \mathrm{~min}$ vs.197.60 $\pm 84.49 \mathrm{~min}$, respectively, $\mathrm{p}=0.022$ ). Postoperative VAS scores at 4 th, 8 th, and 12 th $\mathrm{h}$ at rest were statistically significantly lower in group SA+ESP than group SA $(p=0.004, p=0.046$, $\mathrm{p}=0.044$, respectively).VAS scores during the postoperative 4th, 8 th, and 12 th $h$ cough was statistically significantly lower in group $\mathrm{SA}+\mathrm{ESP}$ than group SA $(\mathrm{p}=0.002$, $\mathrm{p}=0.008, \mathrm{p}=0.028$, respectively).

Conclusions Ultrasound-guided bilateral ESP provided adequate postoperative analgesia and significantly decreased postoperative fentanyl consumption in patients having Caesarean section. Also, it has a longer analgesia time than the control group, and it has been shown to delay the first analgesic requirement. 